\title{
Antioxidant properties of rose extract (Rosa villosa L.) measured using electrochemical and UV/Vis spectrophotometric methods
}

\author{
Anna Masek $^{1, *}$, Malgorzata Latos ${ }^{1}$, Ewa Chrzescijanska ${ }^{2}$, Marian Zaborski $^{1}$ \\ ${ }^{1}$ Technical University of Lodz, Institute of Polymer and Dye Technology, Faculty of Chemistry, 90- \\ 924 Lodz, ul. Stefanowskiego 12/16, Poland \\ ${ }^{2}$ Technical University of Lodz, Institute of General and Ecological Chemistry, Faculty of Chemistry, \\ 90-924 Lodz, ul. Zeromskiego 116, Poland \\ *E-mail: anna.masek@p.lodz.pl
}

doi: $10.20964 / 2017.11 .72$

Received: 19 June 2017 / Accepted: 12 September 2017 / Published: 12 October 2017

The purpose of our study was to analyse the composition and antioxidant properties of phytocompounds in a rose extract (Rosa villosa L.). Spectroscopic and electrochemical methods were used to achieve this goal. UV-Vis and FTIR spectra helped to identify the polyphenols that are present in the tested extract compared with the literature data. Then, oxidation potential using cyclic and pulsed voltammetry was determined $(\mathrm{Ep} \mathrm{I}=0.47 \mathrm{~V}$, Ep II $=0.68 \mathrm{~V}$ and Ep III $=1.58 \mathrm{~V})$. Based on the $\mathrm{CV}$ and DPV parameters, which were determined from the ABTS spectroscopic methods, DPPH, FRAP and CUPRAC evaluated the antioxidant activity of the compounds that are present in the rose extract. Based on TG, the thermal stability of the rose extract was determined. A large correlation was found between the composition and the antimicrobial potential of the plant material tested, which is slightly lower than that of other plant-rich polyphenols (fruits, spices, vegetables). The extraction process itself, as well as the processing of rose fruit, has undoubtedly significantly reduced the antioxidants present in it. However, over-the-counter plant extracts can certainly compete and be an alternative for synthetic compounds, such as Trolox, BHA, and BHT, in cosmetics, food or drugs.

Keywords: Rose; UV-VIS; Electrooxidation; DPV; CPV; Antioxidant

\section{$\underline{\text { FULL TEXT }}$}

(C) 2017 The Authors. Published by ESG (www.electrochemsci.org). This article is an open access article distributed under the terms and conditions of the Creative Commons Attribution license (http://creativecommons.org/licenses/by/4.0/). 